\title{
Flexible Indeterminate Factor-Based Asset Allocation
}

\section{Citation}

Blyth, Stephen, Mark C Szigety, and Jake Xia. 2016. Flexible Indeterminate Factor-Based Asset Allocation. Portfolio Management 42, no. 5: 79-93. doi:10.3905/jpm.2016.42.5.079.

\section{Published Version}

doi:10.3905/jpm.2016.42.5.079

\section{Permanent link}

http://nrs.harvard.edu/urn-3:HUL.InstRepos:27716504

\section{Terms of Use}

This article was downloaded from Harvard University's DASH repository, and is made available under the terms and conditions applicable to Open Access Policy Articles, as set forth at http:// nrs.harvard.edu/urn-3:HUL.InstRepos:dash.current.terms-of-use\#OAP

\section{Share Your Story}

The Harvard community has made this article openly available.

Please share how this access benefits you. Submit a story.

Accessibility 


\title{
FLEXIBLE INDETERMINATE FACTOR-BASED ASSET ALLOCATION
}

\author{
Stephen Blyth ${ }^{1} \quad$ Mark C. Szigety ${ }^{2} \quad$ Jake Xia $^{3}$
}

August 2015

\begin{abstract}
Asset allocation represents a fundamental strategic decision for every institutional investor. Though many asset allocation approaches have been recommended and implemented in various forms, each has its own strengths and weakness. A careful review of current asset allocation frameworks provided motivation to design a hybrid approach that addresses many of these perceived individual shortcomings. Our guiding principle was to use several familiar elements to create a flexible process that incorporates less-quantifiable investment ideas around a rigorous foundation. The result, which we term Flexible Indeterminate Factor-based Asset Allocation (FIFAA), is an adaptive four-step asset allocation synthesis that remains quantitatively and theoretically well grounded. To achieve this goal, FIFAA overlays informed judgment about investment opportunities onto an objectively derived set of core factor exposures.
\end{abstract}

ACKNOWLEDGEMENTS: The authors would like to thank the following people for valuable input and feedback: John Campbell, Edwin Cass, Tham Chiew Kit, Martin Leibowitz, Jay Light, Kevin Pan, Edward Qian, Luis Viceira, and Barbara Zvan. All errors and omissions remain the responsibilities of the authors.

\footnotetext{
${ }^{1}$ President and Chief Executive Officer, Harvard Management Company, and Professor of the Practice of Statistics, Harvard University

${ }^{2}$ Senior Vice President, Harvard Management Company

${ }^{3}$ Chief Risk Officer, Harvard Management Company

Address for correspondence: Harvard Management Company, 600 Atlantic Avenue, Boston MA 02210;

szigetym@hmc.harvard.edu
} 


\section{Introduction}

Asset allocation is arguably the most fundamental strategic investment decision an institution can make-it is also arguably the most challenging. It is therefore no surprise that a bewildering array of approaches have been proposed to help make the asset allocation decision more effective at achieving an institution's long-term goals. It is also no surprise these approaches inevitably involve various practical subtleties and shortcomings that make each a less than perfect solution.

A careful review of current asset allocation frameworks motivated us to design a hybrid approach that for us addresses many of these perceived individual shortcomings. Further, this asset allocation synthesis gives us the important ability to incorporate less quantifiable investment opportunities and concerns. Our guiding principle was to use elements of various asset allocation approaches to create a flexible process around a rigorous foundation, resulting in a comprehensive process that we term Flexible Indeterminate Factor-based Asset Allocation (FIFAA). In the remainder of this article, we will review our understanding of the asset allocation landscape, describe FIFAA, and discuss its practical implications.

\section{Asset Allocation Review}

Since the pioneering work of Markowitz [1952; 1952] and the advent of modern portfolio theory, institutional asset allocation as a practical field has evolved to include myriad techniques and perspectives. Many of these are shown in Exhibit 1, which lists the dominant approaches we reviewed, their return and risk focus, their characteristic process, and any apparent primary shortcomings. To provide context for our approach, we briefly discuss each. 
Exhibit 1. Summary of surveyed asset allocation approaches and perspectives

\begin{tabular}{|c|c|c|c|}
\hline Name & Focus & Process $^{4}$ & Shortcomings \\
\hline Modern Portfolio Theory & \multirow{5}{*}{ Returns and Risk } & \multirow{5}{*}{ Quantitative/Determinate } & input error; often impractical portfolios \\
\hline Mean-Variance Optimization & & & — simple \\
\hline Asset-Liability Management & & & — requires additional liability modeling \\
\hline Black-Litterman & & & — requires additional market knowledge \\
\hline others & & & - etc. \\
\hline Targeted Risk Objectives & \multirow{6}{*}{ Risk } & \multirow{6}{*}{ Quantitative/Determinate } & generally ignores return objectives \\
\hline Risk Parity & & & — often requires leverage \\
\hline Equally-Weighted & & & — ignores potential risk concentrations \\
\hline Minimum Risk & & & — often requires leverage \\
\hline Maximum Diversification & & & — arbitrary solution \\
\hline others & & & - etc. \\
\hline Functional or Risk Categorization & Risk & Qualitative/Indeterminate & potentially arbitrary \\
\hline Best Ideas & Returns and Risk & Qualitative/Indeterminate & may ignore portfolio-wide considerations \\
\hline Endowment Model & Returns and Risk & \multirow{3}{*}{$\mathrm{n} / \mathrm{a}$} & $\begin{array}{l}\text { a philosophy, not a portfolio construction } \\
\text { methodology }\end{array}$ \\
\hline Factors & Returns and Risk & & $\begin{array}{l}\text { a perspective, not a portfolio construction } \\
\text { methodology }\end{array}$ \\
\hline Reference Portfolio & Returns and Risk & & $\begin{array}{l}\text { mapping challenges; not a portfolio construction } \\
\text { methodology }\end{array}$ \\
\hline
\end{tabular}

\footnotetext{
4 "Quantitative" refers to whether the required inputs to the allocation process are predominantly objective and quantifiable. "Qualitative" refers to whether the required inputs to the allocation process are predominantly subjective and not quantifiable. "Determinate" indicates that the approach or perspective as commonly used generally takes a user from the starting inputs to a specific recommendation. "Indeterminate" indicates that the approach or perspective as commonly used generally does not take a user from the starting inputs to a specific recommendation.
} 
Despite its age and familiar shortcomings, modern portfolio theory remains the most popular approach in practice and forms the basis for common mean-variance optimizations and its many related variants. At its commonly understood core, modern portfolio theory involves quantifying the return and risk characteristics of a universe of investments so as to determine, under some specified risk preferences, a mathematically optimized portfolio over some horizon. Variants have grown to include alternate and additional definitions of risk, ${ }^{5}$ alpha considerations (Treynor and Black [1973]), asset-liability management (Liebowitz and Henriksson [1988]), and multiperiod considerations (Samuelson [1969], Merton [1969; 1971; 1973], Campbell and Viceira [2002; 2005]). Today, the chief practical challenge of mean-variance optimization remains the estimation of the many parameters often required, ${ }^{6}$ and the unstable, unintuitive, and often impractical portfolios that estimation error and optimization may generate (Michaud [1989]). Unsurprisingly and consequently, basic mean-variance optimizations have been shown to perform poorly out-of-sample (Chaves et al. [2011], Ang [2014]). Therefore, mean-variance optimization is generally not used as academically intended, but instead to generate a somewhat unsatisfying set of rough takeaways that guide portfolio choice. Fortunately, the instability of mean-variance optimizations has been partially addressed through recommendations on shrinkage operators and random matrix theory (Jorion [1986], Plerou et al. [2002], Sharifi et al. [2004], Bai et al. [2009]), robust optimizations (Ben-Tal and Nemirovski [1998], Quaranta and Zaffaroni [2008]), and incorporating market-derived parameter estimates.

An important and widespread example of the latter market-based solution is the BlackLitterman (Black and Litterman [1992]) approach. In Black-Litterman, expected returns are

\footnotetext{
${ }^{5}$ As two examples, some consider expected shortfall (Rockafellar and Uryasev [2000], Xiong and Idzorek [2011]) and portfolio illiquidity (Hayes et al. [2015]). Also, consider alternative definitions of investor utility (see Campbell and Viceira [2002]).

${ }^{6}$ This broadly includes liability modeling challenges.
} 
derived by backing out market-implied returns using an estimate of the market size and risk and the assumption that every investor is a mean-variance optimizer. From this starting point, an investor may rigorously incorporate their views, adjusted by confidence, into the market-implied return estimates for use in a standard mean-variance optimization. Depending on the investor's confidence and any additional robustness techniques used, the resulting portfolio may resemble the market portfolio with intuitive adjustments corresponding to the stated views. While appealing and despite its assumption of mean-variance investors, Black-Litterman can be challenging for institutional investors who invest in many esoteric areas whose market sizes are only roughly known. ${ }^{7}$

Largely in response to the apparent comparative difficulty of estimating expected returns, investors have introduced a variety of risk-only asset allocation frameworks. Bridgewater’s All Weather strategy represents an early and famous example of such an approach, in which risk is allocated evenly across portfolios that are expected to perform appropriately in each of four separate market environments. This approach, which now can be roughly classified as a type of risk parity (Qian [2005; 2011]), seeks to not only obviate the need to estimate returns, but to also address an apparently overly high concentration to equity risk within institutional portfolios; as a direct result, leverage is typically employed to achieve sufficient portfolio return. Risk parity represents one of a class of what we call "targeted risk objective” approaches, which additionally include equally weighted (often informally termed the “ $1 / n$ ” approach), ${ }^{8}$ minimum risk and maximum diversification portfolios (Clarke et al. [2006], Choueifaty and Coignard [2008]). While targeted risk objective approaches have performed well historically (Chaves et al. [2011],

\footnotetext{
${ }^{7}$ Important work has been done in this area (Doeswijk et al. [2014]), but it remains a stubborn obstacle.

${ }^{8}$ Equally weighting an investment portfolio may be considered a basic form of risk diversification.
} 
Ang [2014]), it is hard to know whether such performance is repeatable. ${ }^{9}$ Practically, there are a variety of other risk-based approaches that we broadly characterize as "functional or risk categorization" that seek to build portfolios that either satisfy an institution's functional needs (e.g., so-called growth assets, opportunistic buckets or safety reserves) or are expected to perform well given beliefs about the evolution of the market environment. ${ }^{10}$ Each of these can suffer from arbitrary classifications and may not directly lead to an obvious strategic recommendation.

Other well-known approaches do not fit easily within a canonical return or risk perspective. The "best ideas" framework, in which asset allocation is a consequence of bottoms-up relative value analysis, and the endowment model, in which long-term investors focus on relatively illiquid alternative assets, are two such examples. Best ideas appeals to the fundamental investor in many of us, but—as it does not directly consider or make recommendations regarding portfolio-wide diversification, risk, and return characteristics-it cannot truly be considered a standalone asset allocation approach. In our view, the endowment model can be classified more appropriately as an investing philosophy or recommendation; or, as fitting within a modern portfolio theory framework in which alternative, often illiquid, assets are believed to have an attractive profile to long-term investors.

A factor perspective has seen a recent resurgence, but it is not a new phenomenon (Sharpe [1964], Ross [1976], Rosenberg and Marathe [1976], Fama and French [1992; 1993], Carhart [1997]). At its core, factor investing focuses the portfolio choice decision on the precise elements of market risk that are rewarded, looking through the sometimes arbitrary asset class

\footnotetext{
${ }^{9}$ The forty-year bull market in U.S. sovereign bonds may substantially bias backtests, for example.

${ }^{10}$ For example, consider a probability-weighted average of $N$ sub-portfolios, each somehow determined to perform best or appropriately in the $n$th market scenario.
} 
classifications. As such, a factor perspective serves two important investment functions: clarity and simplification. For complicated institutional portfolios, this is an attractive feature-made even more so considering that a factor perspective can be applied to many of the approaches we have discussed so far. In practice, factors are used not only as part of a mean-variance analysis or risk-based approach, but implicitly in so-called "reference portfolios”. Prominently discussed and implemented by the Canadian Pension Plan Investment Board (CPPIB) and several other institutions, reference portfolios specify a base portfolio of asset classes that correspond closely to factors on which an institution bases its overall strategic implementation. For example, as of 2014 CPPIB uses a reference portfolio that is $65 \%$ equities and $35 \%$ bonds. To invest $\$ 100$ in private equity, which they consider a leveraged equity investment, CPPIB would sell \$130 of equities and purchase $\$ 30$ of bonds or cash. Inherent in this approach is a mapping of each investment into the asset classes-as-factors reference portfolio for the purposes of maintaining a set strategic exposure. As with all factor modeling, the mapping operation can be practically challenging and exacerbated by a simple or sparse reference portfolio or factor set.

After having comprehensively reviewed these approaches through the lens of our own experiences and with the input from industry peers and academic experts, we formed several tentative conclusions. First, there is no magic bullet or miracle cure to the asset allocation problem: each common approach entails various shortcomings that often prove frustrating in practice. At the root of the issue is that we as a broader community of investors simply have insufficiently precise idea about the evolution of the markets over suitably long investment horizons. Therefore, it follows directly that any realistic framework will to a greater or lesser extent depend on poorly known inputs; and, we believe it is important to focus as much as possible on a minimal set of parameters for which we have a relatively better understanding. To 
this end, we find the greatest inspiration from the literature on factors and the use of reference portfolios; though targeted functional risk approaches like risk parity share this characteristic, their failure to explicitly include return objectives (and their corrective need for leverage) make them less attractive to employ in institutional settings.

Second, modern portfolio theory and its variants remain popular for a reason: they are a rigorous and academically accepted way to combine views on the market and risk preferences into a justifiable portfolio-it is the approach we have used in many forms for many years. But, notwithstanding various techniques to make the optimizations better behaved, there is still the practical reality of "reverse number-crunching": since modern portfolio theory involves pure quantification, and investment committees and Boards may have strong preferences and beliefs that are difficult to quantify, aligning the output of an optimization with well-informed expectations may involve a heavy dose of inefficient parameter manipulation or algorithmic tinkering.

Altogether we perceive an instance of a common tension in finance: on the one hand, investors are eager to apply an off-the-shelf recipe for choosing a portfolio, but at the same time recognize that such procedures may not square with their intuition and understanding about the choices they face and the market environment they inhabit. ${ }^{11}$ This tension calls to mind a guiding logicist argument that a worthy practical approach "balances [the] objective and subjective, and puts aside an operationally spurious concept of [a] true model” (Dempster [1998]). Thus, there is a strong desire for investment committees and Boards to flexibly incorporate best ideas or similar bottoms-up analysis across markets into the strategic asset allocation process, and this recognition forms the basis of our principal conclusion.

\footnotetext{
${ }^{11}$ For a broader commentary on this phenomenon, see Blyth [2013].
} 
In brief, we were motivated to build a process that enabled our organization to express less quantifiable investment ideas and objectives around a rigorous core without resorting to ex post numerical adjustments and justifications. Here we were inspired by Black-Litterman, but were ultimately dissuaded by both its implementation challenges and that its final output remained highly quantitative and determinate. Thus, in general, we did not find such an approach: either a framework was largely quantitative and determinate, or largely qualitative and indeterminate we wanted the final step in our process to be fluid and accommodating, but based on a firm foundation: both quantitative and indeterminate, thereby involving expert opinion and the formalized incorporation of necessarily subjective judgment.

\section{Flexible Indeterminate Factor-based Asset Allocation}

Our proposed solution, which we call Flexible Indeterminate Factor-based Asset Allocation (FIFAA), incorporates features of at least four common frameworks: modern portfolio theory, factors, reference portfolio, and best ideas. Our approach rests on an assumption that our strategic asset allocation, as expressed through asset classes, can be conceived of as a combination of a systematic factor portfolio and a non-systematic "residual" portfolio. By partitioning in this manner, FIFAA focuses on the principle drivers of our risk and return while at the same time accommodating a variety of desirable portfolios and investment opportunities. The approach comprises the four steps shown in Exhibit 2: (i) selecting factors; (ii) measuring asset class or investment universe factor exposures; (iii) choosing desirable factor exposures; and (iv) determining the most appropriate asset class targets and ranges for achieving our long-term investment objectives, which at the same time maintain our preferred factor exposures. 
Exhibit 2. Process steps for Flexible Indeterminate Factor-based Asset Allocation

\begin{tabular}{|c|c|c|c|c|}
\hline \begin{tabular}{|c|c|} 
What are \\
appropriate \\
underlying \\
factors?
\end{tabular} & $\begin{array}{c}\text { How are our asset } \\
\text { classes exposed } \\
\text { to these factors? }\end{array}$ & $\begin{array}{c}\text { What factor } \\
\text { exposures are } \\
\text { desired? }\end{array}$ & $\begin{array}{c}\text { What asset class } \\
\text { portfolios match } \\
\text { our desired factor } \\
\text { exposures? }\end{array}$ \\
\hline
\end{tabular}

\section{Selecting Appropriate Factors}

The first of two steps that focus on setting up the bases within our portfolio choice problem, Step 1 involves the selection of systematic factors. The selection of appropriate systematic factors is a matter of informed judgment, and based on our research we believe there is no ideal set that is appropriate for every institutional investor. Generally, we believe that a parsimonious set of between four and six are enough to span more of the primary risk and return drivers than solely equities and bonds (i.e., more than the most simple reference portfolio), but not too many so as to prevent increased simplicity and heightened confidence in our capital market assumptions.

There are many systematic factor options, including equities, rates, inflation, credit spreads, currency, liquidity, and volatility. ${ }^{12}$ While we believe there is no universally appropriate factor set, there are some selection guidelines we advocate. First, we feel that it is important that the factors suitably capture the essence of an institution's risk and return objectives and general investment strategy. Factors at their best serve as a manageable distillation of the opportunities and concerns of an investor: an institution should be able to express preferences or to conceive of the world in terms of its chosen factor set. Next, the ability to easily and inexpensively trade factors in the market allows an institution to effectively manage its exposure. Parsimony also

\footnotetext{
${ }^{12}$ For excellent references, see Ilmanen [2011] and Ang [2014].
} 
demands that one should carefully assess desired portfolio-wide factor exposure before including what we believe are asset-class specific "residual” factors, such as value, momentum, or carry. ${ }^{13}$ Further, small pairwise relationships among the factors are helpful, though not necessary: low correlations assist with subsequent asset class mapping, but can be managed.

Perhaps the most important selection consideration is how easy it is to form relatively high quality factor risk and return expectations. In fact, one of the primary reasons for using factors within FIFAA is that, in addition to—or perhaps because of-parsimony, an institution can concentrate on better understood underlying drivers of risk and return instead of the often messy dynamics of asset classes. ${ }^{14}$ For this, one should consider the volume of analysis and third-party research each factor has generated. For example, world equity risk premia are extraordinarily well-researched academically, and a variety of consultants and asset managers produce reasonable and clear return estimates. This is similar in many other cases, such as rates, inflation, and currency, but perhaps less so in liquidity and volatility. Risk estimates are similarly available to a greater or lesser degree, and may even be supplemented by accessing and implementing the academic literature on risk modeling and portfolio choice (Campbell and Viceira [2005], Hoevenaars et al. [2008], Van den Goorbergh et al. [2011]).

Exhibit 3 shows just one example of a systematic set of five factors that can be roughly separated into three return-premia and two hedging factors. World equities, the first of the three return-premia factors, represent exposure to the growth that most institutional investors need to increase real purchasing power. U.S. Treasuries, in addition to offering the bond risk premium,

\footnotetext{
${ }^{13}$ These factors are expressed somewhat differently across asset classes, making it more challenging to include them as one or two systematic factors for a multi-asset institutional portfolio.

${ }^{14}$ The equivalence of factors and asset classes has been much debated (Idzorek and Kowara [2013], Cocoma et al. [2015]). Generally, we are of the opinion that factors confer an advantage if they are more manageable to an institution, which thereby enables better decision-making. A key component of this is confidence in the asset allocation inputs.
} 
represent a defensive factor during times of market distress. High yield credit, while arguably similar in nature to equities and sovereign bonds, may serve as an additional explanatory factor for many alternative asset classes. ${ }^{15}$ Inflation protection, the first of the two hedging factors, captures the hedging needs of institutional investors with regard to unexpected changes in the price level. ${ }^{16}$ Finally, the currency factor captures the hedging needs of domestic institutional investors with regard to unexpected changes in the dollar's exchange value, while further serving as protection against market distress. ${ }^{17}$ As a set, we estimate that altogether these tradable five factors account for $85 \%$ to $95 \%$ of a typical domestic institutional investor's risk, are low-tomoderately correlated, and are amenable to relatively confident forecasting.

\footnotetext{
${ }^{15}$ Agarwal and Naik [2004] and Jaeger and Wagner [2005] note that high yield may be an explanatory factor for some hedge funds that focus in distressed areas. Fung and Hsieh [2002], in an analysis of fixed-income hedge fund styles, find evidence that certain common components are related to a high yield factor; Ennis and Sebastian [2003] uncover varying hedge fund exposures over time to high yield. We believe that the high yield factor may reasonably proxy for the "short put" aspect of many hedge funds' strategies (Goetzmann [2002]; Lo [2001]; Siegmann and Lucas [2002]; Jurek and Stafford [2015]). Within private equity, there is a desire to invest in distressed companies through both equity and debt, suggesting direct exposure to the high yield factor. Within real estate, there is also evidence that higher-yielding credit factors may be helpful in explaining returns (He et al. [2003]; Chan et al. [1990]; Sanders [1996]). Note as well that Chen et al. [1986] and Fama and French [1993] make the case that interest rates related to corporate default risk are primary capital market factors.

${ }^{16}$ Not only is unexpected inflation useful as a real value hedge for liability management (see Leibowitz and Henriksson [1988]), but may also be useful in explaining asset class behavior (Bodie [1976]; Nelson [1976]; Jaffe and Mandelker [1976]; Fama and Schwert [1977]; Chen et al. [1986]; Elton et al. [1995]; Brandt and Wang [2003]; Ludvigson and Ng [2009]).

${ }^{17}$ Similar to the unexpected inflation factor, unexpected changes in the dollar exchange rate is not only useful as a hedge for liability management, but may also be useful in explaining asset class behavior (Agarwal and Naik [2004]; Hasanhodzic and Lo [2007]; Ferson and Harvey [1993]; Chow et al. [1997]). Further, there is general consensus regarding the advantages of hedging foreign currency exposure in fixed income and developed equities (Perold and Schulman [1988]; Kritzman [1993]; Eun and Resnick [1988]; Campbell et al. [2010]). In general and at a high level, the dollar factor allows us to express portfolio-wide hedging preferences.
} 
Exhibit 3. Example of a five factor set

\begin{tabular}{|c|c|c|c|c|}
\hline Factor & Suitable & Tradable & $\begin{array}{c}\text { Correlation } \\
\text { Impact }^{\mathbf{1 8}}\end{array}$ & $\begin{array}{c}\text { Relative } \\
\text { Confidence }\end{array}$ \\
\hline $\begin{array}{c}\text { World Equities } \\
\text { (cap-weighted world equity index) }\end{array}$ & Yes & Yes & Moderate & Moderate \\
\hline $\begin{array}{c}\text { U.S. Treasuries } \\
\text { (U.S. Treasury index) }\end{array}$ & Yes & Yes & Low & High \\
\hline $\begin{array}{c}\text { High Yield } \\
\text { (high yield index) }\end{array}$ & Yes & Yes & Moderate & High \\
\hline $\begin{array}{c}\text { Inflation Protection } \\
\text { (long Treasuries, short TIPS) }\end{array}$ & Yes & Yes & Low & High \\
\hline $\begin{array}{c}\text { Currency Protection } \\
\text { (long USD, short cap-weighted foreign) }\end{array}$ & Yes & Yes & Low & High \\
\hline
\end{tabular}

\section{Mapping Asset Classes}

The second step involves determining how asset classes or investment universes relate to the selected factors. One of the attractive features of FIFAA is that it is flexible enough to easily incorporate many asset classes or investment opportunities. As just one example, one can separate emerging market equities into commodity exporters and importers under the assumption that commodity exporters such as Brazil, South Africa, Mexico and Russia have different factor exposures than commodity importers such as China, South Korea, Taiwan, and India. As another, consider the significant differences among hedge fund strategies, from fundamental global macro funds to CTAs. Thus, the second step in FIFAA involves determining both a potential set of asset classes or investment universes and how they map to our selected factors.

The end result of this step is a matrix of linear exposures (or so-called "betas") for use in a variety of subsequent stages, an example of which is shown in Exhibit 4. To arrive at this matrix, we proceed from two directions. First, whenever possible and appropriate, we employ empirical approaches to pin down a parsimonious set of estimated exposures. Second, together

\footnotetext{
${ }^{18}$ Correlation impact is a rough assessment based on each factor's Variance Inflation Factor, which assesses the degree to which a given factor is explained by the other factors in the factor set. See O’Brien [2007].
} 
with our portfolio managers, we formally incorporate necessarily subjective market-informed overlays to ensure the estimates appear appropriate on a forward-looking basis.

Since we value simplicity and parsimony, for any empirical analysis we recommend using methodologies that limit the number of identified relationships between the asset classes and factors. The most common methodology of this class is some type of subset selection (or socalled "stepwise") model that systematically adds or removes factor relationships as per their statistical power to explain asset class behavior. ${ }^{19}$ However, we generally prefer using LASSO (Tibshirani [1996]) with cross-validation. LASSO by its very construction has the advantage of mathematically ensuring a parsimoniously estimated model. ${ }^{20}$ While generally used for reducing large sets of covariates done to a manageable size, we find that it works well for factor analysis.

There is good reason to be skeptical of estimated relationships: historical behaviorespecially for some of the more alternative or novel asset classes-may not be indicative of future behavior. Nonstationarity pervades financial markets; data can be limited; factors, collinear. Nevertheless, in many cases empirical results can serve as a useful prior for further analysis. This further analysis invariably involves overlaying ex ante exposure expectations based on expert judgment or fundamental models. We find the best method for arriving at these

19 An example of a subset selection model is a simple "forward-stepwise” algorithm. First, fit the data (via OLS) to each of the factors one-by-one. If any of the trial factors have p-values less than $5 \%$, add the one with lowest pvalue; if any of the current factors have p-values greater than $10 \%$, remove the one with the highest $\mathrm{p}$-value. Run the new model with the remaining trial factors one-by-one and repeat these steps until no additional factors are added or dropped.

${ }^{20}$ One implementation of LASSO solves the following minimization problem:

$$
\alpha, \beta=\underset{\alpha, \beta}{\operatorname{argmin}}\left(\frac{1}{2 T} \sum_{t=1}^{T}\left(r_{t}-\alpha-f_{t}^{\prime} \beta\right)^{2}+\lambda \sum_{i=1}^{m}\left|\beta_{i}\right|\right)
$$

where $\alpha$ is the estimated constant, $\beta$ is the $m \times 1$ vector of estimated factor exposures, $T$ is the number of observations, $r_{t}$ is the observed asset class benchmark return at time $t, f_{t}$ is the $m \times 1$ vector of observed factor returns at time $t, \lambda$ is the estimated coefficient penalty parameter, and $m$ is the number of factors. For each asset class, select the value of $\lambda$ that minimizes the average out-of-sample mean-squared error after a $k$-fold cross validation. 
conclusions is structured conversations with portfolio managers and industry practitioners. These conversations help resolve, for example, questions regarding appropriate models of private equity, the expected inflation response of commodity producing countries, and other aspects of exposure that historical estimations may fail to capture.

In some cases, portfolio managers have rough numerical views regarding the factor exposures. Generally, these are based on an understanding of their investment universes response to recent movements in one factor. Since many related factors in our "multi-factor model” are also moving at the same time, these rough numerical views based on inherently a "single-factor model" view of the world appear to be of little value. However, an inversion of the well-known result for omitted variable bias under an assumption about factor return behavior allows us to evaluate and possibly make use of this information. See the Appendix for details on this important transformation, which has general applicability in many other contexts.

Exhibit 4. Example of an asset class mapping matrix

\begin{tabular}{|c|c|c|c|c|c|}
\hline & $\begin{array}{c}\text { World } \\
\text { Equities }\end{array}$ & $\begin{array}{c}\text { U.S. } \\
\text { Treasuries }\end{array}$ & High Yield & $\begin{array}{c}\text { Inflation } \\
\text { Protection }\end{array}$ & $\begin{array}{c}\text { Currency } \\
\text { Protection }\end{array}$ \\
\hline U.S. Equities & 1.0 & & & 0.1 & 0.5 \\
\hline Foreign Equities & 1.0 & & & 0.1 & -0.5 \\
\hline Private Equity & 1.3 & & 0.2 & 0.1 & 0.3 \\
\hline Real Assets & 0.3 & & 0.8 & 0.3 & \\
\hline Commodities & & & & 2.0 & -0.5 \\
\hline U.S. Treasuries & & 1.0 & & & \\
\hline TIPS & & 1.0 & & 1.0 & \\
\hline Corporate Bonds & & 0.8 & 0.2 & & \\
\hline Foreign Bonds & & 0.8 & & & -1.0 \\
\hline Absolute Return & 0.2 & & 0.2 & & \\
\hline
\end{tabular}




\section{Choosing Factor Exposures}

Moving on to the two portfolio selection stages, the third step involves selecting desired or optimal factor (not asset class) exposures using insights from a variety of return- and risk-based approaches and filtered through the lens of an institution's overall investment objectives and

tolerances. While we favor modern portfolio theory options because of their quantitative rigor and focus on the return/risk tradeoff, there is no reason why an institution cannot use any approach it wishes to arrive at a uniquely appropriate set of exposures. In fact, this stage likely benefits from a broader view, simply because no one construction approach dominates. The most important result of this step is for an institution to feel confident that the selected exposures form an ideal base on which to more fully develop a strategic asset allocation.

This is easier said than done, of course. If pursuing a mean-variance route, one can start by aggregating capital market assumptions-possibly including liabilities and Black-Litterman inputs - and perform various constrained, robust optimizations or stress simulations. This tactic's main advantage lies in its relative objectiveness, but its main disadvantage lies in its recommending exposures without an overall asset class portfolio context. Though by no means necessary, a helpful alternative is to establish a base set of factor exposures by using the estimated asset class mapping from Step 2 and applying it to either our current strategic portfolio or a representative industry sample. Armed with the knowledge of an implied set of optimal exposures, one may employ various constrained mean-variance approaches to adjust these exposures based on relatively better understood capital market assumptions. This approach's main disadvantage lies in its anchoring to possibly arbitrary exposures, but it does provide a starting point for an informed discussion. Further, since an institution’s strategic factor loadings should preferably change only slowly, current exposures seem a natural place to start. 
Exhibit 5 shows an example of each approach. The traditional, hedged portfolio is an exogenously built portfolio that is similar to a traditional 60/40, but-because of concerns about inflation and currency risk—-has a significant loading on those hedging factors. The implied exposures in the second row, which are derived from a hypothetical portfolio that we feel is reasonably representative of institutional investors, ${ }^{21}$ form the basis for a constrained optimization, whose output is in the third row. ${ }^{22}$ This analysis suggests that a better systematic risk-return profile than the implied could be achieved by increasing exposure to the high yield factor, increasing the diversification benefits of U.S. Treasuries, reducing inflation protection, and hedging foreign currency risk. Note that this analysis aggregates the currency hedging analysis effectively across asset classes, making it unnecessary to answer the question of individual asset class hedging. Of course, this is only an illustrative example and not meant as a specific recommendation: indeed, employing an asset-liability management approach may very well suggest an increase in inflation protection compared with the implied exposure, not a decrease as below.

Exhibit 5. Examples of potential target factor exposures

\begin{tabular}{|c|c|c|c|c|c|}
\hline & $\begin{array}{c}\text { World } \\
\text { Equities }\end{array}$ & $\begin{array}{c}\text { U.S. } \\
\text { Treasuries }\end{array}$ & High Yield & $\begin{array}{c}\text { Inflation } \\
\text { Protection }\end{array}$ & $\begin{array}{c}\text { Currency } \\
\text { Protection }\end{array}$ \\
\hline $\begin{array}{c}\text { Traditional, } \\
\text { Hedged }\end{array}$ & $\mathbf{0 . 6 0}$ & $\mathbf{0 . 4 0}$ & $\mathbf{0 . 0 0}$ & $\mathbf{0 . 2 5}$ & $\mathbf{0 . 2 5}$ \\
\hline Implied & 0.66 & 0.19 & 0.15 & 0.19 & 0.06 \\
\hline Optimal & $\mathbf{0 . 6 5}$ & $\mathbf{0 . 2 4}$ & $\mathbf{0 . 2 0}$ & $\mathbf{0 . 1 4}$ & $\mathbf{0 . 1 1}$ \\
\hline
\end{tabular}

\footnotetext{
${ }^{21}$ The weights are 20\% U.S. Equities, 15\% Foreign Equities, 20\% Private Equity, 10\% Real Assets, 5\% Commodities, 15\% U.S. Treasuries, 0\% TIPS, 5\% Corporate Bonds, 0\% Foreign Bonds, 10\% Absolute Return. ${ }^{22}$ Constrained to deviate no more than 0.05 for each initial exposure, and targeting the same risk implied by the factor exposures and a hypothetical expected covariance matrix (not shown).
} 
An appropriately chosen set of factor exposures should represent an institution's fundamental risk and return posture, from which actual strategic market expression derives. Since properly selected and attributed factors will often represent over $90 \%$ of an institution's risk, the factor exposures - like a reference portfolio — should be conceived of as the stable, core driver of an institution's long-term objectives. However, unlike common reference portfolio implementations, there is no requirement that the factor exposures sum to $100 \%$ : in fact, implicit or explicit leverage may be embedded. This permits, for example, a high returning set of exposures expressible partly through the embedded leverage in private equity buyouts, without requiring an offsetting purchase of bonds or cash as in the CPPIB example. It also permits exposure to cashless factors, such as currency protection, through fully funded hedged or unhedged foreign investments. We believe that many asset classes and universes have leveraged factor exposures, and-provided the factor exposures are considered appropriate by the institution - there is no reason to arbitrarily limit them.

\section{Selecting an Asset Class Portfolio}

The final and crucial step in the process is to express the factor exposures through various investments and asset classes to form the final strategic asset allocation. In contrast to the more stable base of the factor exposures, asset classes and investment universes are more heterogeneous, dynamic, fluid, tactical, and innovative. They often come in and out of existence, change character, and reflect current investment themes. We believe that they best serve to augment and to manifest systematic factor exposures, as well as confer some additional return premia or alpha opportunities. In many cases, harvesting additional premia will be necessary to enhance the systematic portfolio's return in accordance with the institution's long-term 
objectives. The main challenge in selecting appropriate strategic asset class weights and ranges - and the main opportunity for incorporating best ideas-is that, in general, there is an infinite number of portfolio solutions that satisfy the institution’s desired factor exposures.

This "indeterminacy" is the key element of FIFAA, and results from the simple fact that there are many more collections of investments or asset classes than there are primary factors. Thus, there are many ways asset classes can combine to give the same systematic exposures. We have identified three ways to manage and to exploit this indeterminacy within FIFAA. First, an institution can fully embrace best ideas, basing the portfolio entirely on a bottoms-up analysis of investment opportunities. Provided that the opportunities are mapped as in Step 2, exposure deviations theoretically may be managed through derivatives. However, because of the implicit leverage, position sizes, and obvious potential for liquidity mismatches, this seems to be only appropriate when a bottoms-up portfolio coincidentally maps closely to the desired exposures. This is typically the case for day-to-day implementation within asset classes.

A second more practical approach involves generating a permissible set of asset class portfolios that match the factor exposures. Using well known properties of pseudo-inverses within the context of indeterminate systems of equations, it is possible to calculate an extremely large set of allowable portfolios. ${ }^{23}$ From this set of allowable portfolios, filters can be applied to winnow the portfolios down-if possible — to those that jointly display certain characteristics

${ }^{23}$ The complete solution set to an indeterminate linear system is given by:

$$
W=\theta_{\beta}{ }^{\prime g} F+\left(\mathrm{I}-\theta_{\beta}{ }^{\prime g} \theta_{\beta}{ }^{\prime}\right) v
$$

where $W$ is a $n \times 1$ vector of asset class weights, $\theta_{\beta}$ is the $n \times m$ exposure matrix, $F$ is the $m \times 1$ vector of targeted factor exposures, I is a $n \times n$ identity matrix, the superscript $g$ indicates a generalized inverse (in this case, the MoorePenrose pseudoinverse), and $v$ is any $n \times 1$ vector.

To generate a large number of permissible solutions, a large number of $v$ vectors composed of iid $\mathrm{U}(0,1)$ elements are generated and used to produce a large number of candidate asset class weights. Weight vectors that do not match required characteristics (e.g., sum to one) are then discarded. The average of the remaining sets of weights may then be computed, or a particular portfolio may be selected. Note that no objective function is used to arrive at the candidate portfolios. 
(e.g., budget and leverage constraints) and incorporate best ideas (e.g., a particular concentration in one or more asset classes). Some number of these portfolios can then be reviewed and compared however informally to others that also pass the criteria in order to select a final strategic asset allocation, or-more straightforwardly—weights can be averaged across the candidate portfolios. A principle advantage of this method is that it fully incorporates difficultto-quantify best ideas into the rigorous factor exposure foundation; a principle disadvantage is a possibly inefficient—or even impossible—portfolio search given stated preferences.

A final, and from our standpoint generally preferred, approach involves a second optimization and requires some amount of quantification. The extent of the quantification can range from simple ordered asset class preferences to fully specifying residual return, risk, liquidity and leverage costs, and other asset class specific measures. Ultimately, the goal is to specify a quantifiable objective function so as to employ well-known optimization techniques to efficiently search for optimal asset class portfolios. Similar to Roncalli and Weisang [2012], who describe a method to ensure portfolios have equal factor exposures, this second optimization treats the desired factor exposures as a constraint. But that need not be so: an optimization constraint may be incorporated into the objective function using an extremely high penalty parameter. In fact, having the factor exposures as a constraint for the optimization is tantamount to saying that the organization deems the factor exposures so paramount that it would be exceedingly painful to deviate from them.

This usage of factors as a constraint or severe penalty within this second optimization is quite different from traditional factor-based mean-variance analysis. In the traditional approach, factors (and residual return and risk estimates) are used to simplify investment modeling for eventual use in a larger-scale single-stage constrained mean-variance optimization. Two 
differences in this canonical approach are apparent: first, the standard approach requires residual return and risk estimates; second, it does not in general provide portfolio solutions that maintain desired factor exposures. In our approach, having the desired factor exposures explicitly accounted for focuses the optimization, howsoever quantified, on finding suitable matching portfolios. In many ways, treating the factor exposures as our approach does creates a distinction between the confidence in an institution's views on the factor exposures (and accompanying mapping) and its less-quantifiable, possibly ordered best ideas and cost preferences. It attempts to satisfy these harder-to-evaluate views, but keeps us from straying too far from what we strongly believe to be satisfactory long-term factor exposures. ${ }^{24}$

Exhibit 6. Example of final asset class portfolios

\begin{tabular}{|c|c|c|c|c|}
\hline & Original & Inverted & $\begin{array}{c}\text { Preference } \\
\text { Score } \\
\text { (1=highest) }\end{array}$ & Optimized \\
\hline U.S. Equities & $20 \%$ & $18 \%$ & 1 & $15 \%$ \\
\hline Foreign Equities & $15 \%$ & $5 \%$ & 4 & $5 \%$ \\
\hline Private Equity & $20 \%$ & $28 \%$ & 1 & $30 \%$ \\
\hline Real Assets & $10 \%$ & $13 \%$ & 2 & $15 \%$ \\
\hline Commodities & $5 \%$ & $1 \%$ & 5 & $2 \%$ \\
\hline U.S. Treasuries & $15 \%$ & $9 \%$ & 1 & $23 \%$ \\
\hline TIPS & $0 \%$ & $2 \%$ & 5 & $0 \%$ \\
\hline Corporate Bonds & $5 \%$ & $12 \%$ & 2 & $0 \%$ \\
\hline Foreign Bonds & $0 \%$ & $4 \%$ & 3 & $2 \%$ \\
\hline Absolute Return & $10 \%$ & $8 \%$ & 2 & $8 \%$ \\
\hline Cash & $0 \%$ & $0 \%$ & - & $0 \%$ \\
\hline
\end{tabular}

${ }^{24}$ A particular advantage of incorporating factor deviations as a penalty allows an institution to tune the penalty depending on the confidence it has regarding either the mapping of the asset classes or the original exposure selection analysis. 
Exhibit 6 shows sample asset class portfolios using the second and third approaches described above and targeting the "optimal" factor exposures in Exhibit $5 .{ }^{25}$ First, FIFAA generates portfolios that are significantly different from the original hypothetical weights, despite having factor exposures that are only modestly different. Second, even when constraining the factor exposures to be equal, FIFAA permits very different portfolios, as can be seen by comparing the inverted and optimized portfolios. Also, notice that the preference score, which captures hypothetical best ideas thinking about opportunities within and across asset classes, induces sensible variations from the original and inverted portfolios. Preferred asset classes, such as U.S. equities, private equity and U.S. Treasuries continue to have either large or increased weights, while (for this hypothetical example) relatively unappealing asset classes such as foreign equities, commodities, and TIPS have small or reduced weights. These portfolios are only two of an extremely large set of variations that FIFAA can accommodate; any number of considerations could theoretically be incorporated into the final portfolio choice.

${ }^{25}$ For the "optimized" portfolio, the following optimization was performed:

$$
\begin{aligned}
& W=\underset{W}{\operatorname{argmin}}\left(W^{\prime} S\right) \\
& \text { s.t. }\left\{\begin{array}{c}
\theta_{\beta}{ }^{\prime} W=F \\
\max \left(W^{0}-10 \%, 0\right) \leq W \leq \max \left(W^{0}+10 \%, 100 \%\right) \\
W^{\prime} 1=1
\end{array}\right.
\end{aligned}
$$

where $W$ is a $n \times 1$ vector of asset class weights, $S$ is the $n \times 1$ vector of preference scores, $\theta_{\beta}$ is the $n \times m$ exposure matrix, $F$ is the $m \times 1$ vector of targeted factor exposures ("Optimal" in Exhibit 5) and $W^{0}$ is the $n \times 1$ vector of original asset class portfolio weights. A variant of this optimization is to place the first compound constraint as a penalty in the objective function (effectively relaxing it, depending on the vector of associated penalty parameters). 


\section{Rebalancing}

Once the strategic asset allocation has been determined, market returns, implementation frictions, and tactical positioning will cause the actual portfolio to deviate from it. This naturally leads to several important portfolio and risk management questions, such as when to rebalance asset classes and when to adjust factor exposures.

To provide context for rebalancing, we leverage the steps of FIFAA to calculate asset class ranges. Asset class ranges, which specify the lower and upper bounds that an asset class may achieve before triggering a systematic rebalancing, appear to be a common feature among institutional investors. This convention has been adopted for good reason: maintaining a fixed asset class allocation is costly in terms of trading or alternatively requires exceptional tracking error estimates, and may needlessly take up expensive management time. From our perspective, it is not even clear that the asset allocation weights should be considered sacrosanct: it is the factor exposures that we care most about. Thus to set reasonable asset class ranges within FIFAA, we make use of the fact that our asset class mapping matrix from Step 3 is imperfectly known. Within our last step and wherever we make mathematical use of our asset class mapping matrix, we add a small amount of error to the betas ${ }^{26}$ and repeat the last step many times. Similar to a robust optimization approach, we then examine the behavior of the resulting asset class portfolios and use a heuristic (e.g., the $25^{\text {th }}$ and $75^{\text {th }}$ percentiles) to establish reasonable ranges.

\footnotetext{
${ }^{26}$ Depending on relative confidence, some betas may have bigger error adjustments than others. For example, if an asset class theoretically matches a factor exactly (like U.S. Treasuries would in our example), it does not make sense to add an error adjustment; other betas (like commodities in our example) may have greater uncertainty.
} 
The rationale for this treatment is simply that we assume one has less confidence in the asset class mapping than in the factor evaluation. ${ }^{27}$ Conceptually, each run of the last "robust" step could arguably be the truly best portfolio to match one's preferred factor exposures - there is no way to tell for sure given the uncertainty. Therefore using these trial runs to form ranges makes sense, and we have additionally found that the width of the ranges varies intuitively. Sometimes an asset class may be crucial for achieving certain factor exposures, and regardless of any beta error in the mapping matrix their corresponding ranges are naturally narrow; other asset classes may be similar in exposures to others (and therefore less important to factor expression) and small amounts of beta error can result in wide ranges.

Of course, setting asset class ranges independently as we do above ignores the joint portfolio dependence among them. However, this subtlety is addressed by proceeding down a separate risk management avenue. In particular, as asset class weights vary within ranges, we can use our Step 2 mapping matrix (with error) to continually assess when we are too far from our stated factor exposures. ${ }^{28}$ In these cases, we are then able to trade derivatives that track our factors up to some pre-determined notional amount. ${ }^{29}$ In cases where we are far from our targeted factor exposures and we have reached a derivatives limit, we would aim to rebalance our asset class exposure as efficiently as possible.

We would ideally assess our factor exposures at the individual investment level because a complete census of our current investments' exposures would permit a more accurate assessment of deviation from the selected factor exposures. Though we know of some asset managers and institutions that have managed to measure investment-specific betas in a broad multi-asset

\footnotetext{
${ }^{27}$ We can employ a similar robust optimization approach when selecting factor exposures. However, once we settle on factor exposures, we treat these as known with certainty.

${ }^{28}$ To do this, we apply the same error to the mapping matrix, fix the asset class weights, and assess the joint likelihood of the factor exposures not equaling the target exposures at some firm-specific confidence level.

${ }^{29}$ As dictated by derivative liquidity, pricing, and leverage concerns.
} 
portfolio, this is challenging in practice due to data availability, high idiosyncratic risk, and required resources.

\section{Discussion}

We believe that FIFAA borrows strength from several attractive asset allocation approaches and perspectives, while at the same time limiting some of their perceived practical weaknesses. Inspired by reference portfolios, FIFAA relies on factors for their parsimony, relative clarity, and flexibility, but expresses a strategic portfolio in the richer, more complex, and familiar perspective of asset classes. It makes use of modern portfolio theory's rigor and accessibility when selecting factor exposures, but does not rely on its quantitative determinism to set our asset class allocations. Finally, FIFAA incorporates less-quantifiable and fundamentally appealing best ideas, but applies them as an overlay to an otherwise carefully structured asset allocation.

Setting our portfolio in terms of asset classes and not factors is a crucial practical aspect. While it is tempting to select one or the other as the portfolio choice basis, to do so removes the inherent flexibility of our approach. At a theoretical level, FIFAA only requires a mapping from a larger to a smaller investment universe, while primary investment objectives are set within the smaller. Then, implementation within the larger universe provides the core indeterminacy and flexibility to incorporate best ideas and less-quantifiable strategic objectives. ${ }^{30}$ It just so happens that asset classes and primary market factors may serve these roles effectively. So, in response to the question: asset classes or factors? We answer: both.

As we expressed earlier, we believe that every common asset allocation perspective or approach suffers from some practical or theoretical weaknesses. Just because FIFAA is designed

\footnotetext{
${ }^{30}$ In many ways, FIFAA is the institutional asset managers' analog to the active portfolio management style of equity managers who rely on risk models to manage industry, sector, and country factors.
} 
as a synthesis does not mean that it is immune to some important limitations; one might say that the set of asset allocation approaches is convex. The first issue is that selecting factor exposures can be challenging without a reasonable understanding of what a constrained portfolio of asset classes might be able to achieve. Some factor exposures are simply not practically attainable given the asset class universe and constraints under consideration. For this concern we recommend two mitigants: (1) establish an initial set of factor exposures from self-analysis or an industry sample as in Exhibit 5 or (2) ensure that the selected factors are tradable and will conform to additional budget or leverage constraints.

A second concern is that FIFAA relies on mean-variance (or any other portfolio choice framework) to select factor exposures. Therefore, the choice of factor exposures may be subject to all the weaknesses and benefits of the approaches previously touched on. Here, in our implementation we rely on standard industry mitigants for mean-variance optimization, and the essential fact that FIFAA is not solely dependent on the outcome of this factor analysis. Note as well that our approach does not jointly consider the return and risk of the entire portfolio, only those of the underlying factors. Therefore, the final portfolio may not have the highest ex ante Sharpe ratio, which results from the fact that the initial factor optimization does not consider the residual return or risk of the eventual asset class implementation. ${ }^{31}$ To limit the potential for a substantially sub-optimal final portfolio, it becomes imperative to ensure that the factor analysis covers as much as possible of the expected risk and return behavior of the eventual portfolio, but not too much to disallow the inherent flexibility to incorporate best ideas or to reduce confidence in the systematic risk and return estimates.

\footnotetext{
${ }^{31}$ We would argue that we have less faith in the Sharpe ratio estimates when the residual return and risk are accounted for, simply because we feel we only have relative confidence in the core factor return and risk estimates.
} 
A third challenge is that we use a mapping matrix which can be difficult to estimate on a forward, longer-term basis. Besides employing robust statistical techniques and expert judgment, we recognize this issue through the application of error within the mapping matrix to establish permissible ranges. In addition, since FIFAA does not necessarily require an estimate of residual risk and return to generate appropriate asset class portfolios, total portfolio return and risk numbers may be only partially known. To address this, some may find it valuable to estimate these asset class specific quantities for use in the final Step 4 optimization.

Lastly, we cannot backtest FIFAA because of the significant amount of essential judgment involved that is hard to quantify. Consequently, we cannot state for sure that FIFAA leads to better objective performance measures (e.g., Sharpe ratios) than other frameworks. To the extent that setting the factor exposures is based on mean-variance or targeted risk approaches such as risk parity, there may be some rough analogies that can be drawn from the literature. But, such analogies would only apply to the core exposures of the eventual asset allocation—not the indeterminate asset class overlay—and thus would be an extremely noisy estimate of eventual performance. Ultimately, the initial value of FIFAA must be determined through its perceived investment and organizational effectiveness. Over time, this should manifest in superior performance.

\section{Conclusion}

Many of the better known asset allocation approaches fall into two opposing groups. On one side are essentially inchoate frameworks like best ideas that take often qualitative inputs and do not lead directly to a unique investment portfolio. On the other are strict approaches like meanvariance optimization that take quantitative inputs into a uniquely structured allocation. FIFAA 
was designed as a hybrid approach to attempt to capitalize on the strengths of each, while limiting their inherent weaknesses. The result is a flexible, indeterminate four-step asset allocation approach that remains quantitatively and theoretically well grounded, which we believe to be additive to existing work.

Since FIFAA is as much a process framework as it is a methodology, each of our four steps can be further refined. In particular, continuing to enhance our confidence in the mapping matrix and applying the approach across individual investments is a key area for further research. In addition, we would like to be able to incorporate as many non-quantifiable preferences as possible during the selection of the asset class portfolio. This involves another avenue of future work developing or implementing an efficient, non-mathematical search through permissible portfolios. Notwithstanding these and other areas ripe for further development, we believe that our introduction to Flexible Indeterminate Factor-based Asset Allocation provides a new perspective on the immensely challenging work of effectively setting an institution's strategic investment portfolio. 


\section{Appendix}

Portfolio managers and analysts frequently conceive of market exposures in a single-factor sense. This generally creates inference challenges in multifactor modeling contexts, as such single-factor betas are often plagued by omitted variable bias (see Goldberger, [1991]). To use single-factor betas in a multi-factor setting, it is simply necessary to correct for this bias by making an assumption about the factor covariance structure as manifested through factor returns.

The math is straightforward. The OLS bias in a single-factor beta $\beta_{f}{ }^{*}$ in the presence of omitted variables is known to be:

$$
\beta_{f}^{*}=\left(1 F_{f}\right)\left(\begin{array}{c}
\beta_{f} \\
\beta_{! f}
\end{array}\right)
$$

where $F$ is the $1 x(m-1)$ vector of single-factor regression coefficients of the factor $f$ on all other factors (one-by-one), $\beta_{f}$ is the unbiased multifactor beta for factor $f$ and $\beta_{!}$is the $(m-1) \times 1$ vector of unbiased multifactor betas of all other factors not including $f$. Re-ordering, ignoring any regression constants, and stacking (1) yield:

$$
\beta^{*}=F \beta
$$

where $\beta^{*}$ is the $m \times 1$ vector of biased betas, $F$ is the $m \times m$ matrix of single-factor betas of each factor on every other factor, and $\beta$ is the $m \times 1$ vector of unbiased betas. $F$ is structured with ones on the diagonal, and every element $i, j$ corresponds to the regression of factor $i$ on factor $j$ (with or without a constant). Simple inversion of (2) yields the result:

$$
\beta=F^{-1} \beta^{*}
$$

Operationally, take the biased single-factor beta estimates, stack them into an $m \times 1$ matrix, calculate $F$, invert it, and finally multiply it into the biased beta estimates to recover the unbiased multi-factor betas. 


\section{References}

Agarwal, Vikas, and Narayan Y Naik. "Risks and Portfolio Decisions Involving Hedge Funds."

Review of Financial Studies 17, no. 1 (2004): 63-98.

Ang, Andrew. Asset Management: A Systematic Approach to Factor Investing. Oxford University Press, 2014.

Bai, Zhidong, Huixia Liu, and Wing-Keung Wong. "Enhancement of the Applicability of Markowitz's Portfolio Optimization by Utilizing Random Matrix Theory." Mathematical Finance 19, no. 4 (2009): 639-667.

Ben-Tal, A. and A. Nemirovski. "Robust Convex Optimization." Mathematics of Operations Research 23, no. 4 (1998): 769-805.

Black, Fischer, and Robert Litterman. "Global Portfolio Optimization." Financial Analysts Journal 48, no. 5 (1992): 28-43.

Blyth, Stephen. "Of Wranglers and Bankers: Reflections on Applied Statistics from a Career in Finance." Chance 26, no. 2 (2013): 4-7.

Bodie, Zvi. "Common Stocks as a Hedge Against Inflation." Journal of Finance 31, no. 2 (1976): 459-470.

Brandt, Michael W, and Kevin Q Wang. "Time-varying risk aversion and unexpected inflation." Journal of Monetary Economics 50 (2003): 1457-1498.

O’Brien, Robert M. "A caution regarding rules of thumb for variance inflation factors." Quality \& Quantity 41, no. 5 (2007): 673-690. 
Campbell, John Y, Karine Seraty-De Medeiros, and Luis M Viceira. "Global Currency

Hedging." Journal of Finance 65, no. 1 (2010): 87-121.

Campbell, John Y and Luis M. Viceira. Strategic Asset Allocation: Portfolio Choice for LongTerm Investors. Oxford University Press, 2002.

Campbell, John Y and Luis M. Viceira. "The Term Structure of the Risk-Return Trade-Off." Financial Analysts Journal 61, no. 1 (2005): 34-44.

Carhart, M. "On Persistence in Mutual Fund Performance." Journal of Finance 52, no. 1 (1997): 57-82.

Chan, K.C., Patric H Henderschott, and Anthony B Sanders. "Risk and Return on Real Estate: Evidence from Equity REITs." Journal of the American Real Estate and Urban Economics Association 18, no. 4 (1990): 431-452.

Chaves, Denis, Jason Hsu, Feifei Li, and Omid Shakernia. "Risk Parity Portfolio vs. Other Asset Allocation Heuristic Portfolios." Journal of Investing 20, no. 1 (2011): 108-118.

Chen, Nai-Fu, Richard Roll, and Stephen A Ross. "Economics Forces and the Stock Market." Journal of Business 59, no. 3 (1986): 383-403.

Choueifaty, Yves, and Yves Coignard. "Toward Maximum Diversification." Journal of Portfolio Management 34, no. 4 (2008): 40-51.

Chow, Edward H, Wayne Y Lee, and Michael E Solt. "The Exchange-Rate Risk Exposure of Asset Returns." Journal of Business 70, no. 1 (1997): 105-123. 
Clarke, Roger, Harindra de Silva, and Steven Thorley. "Minimum-Variance Portfolios in the U.S. Equity Market." Journal of Portfolio Management 33, no. 1 (2006): 10-24.

Cocoma, Paula, Megan Czasonis, Mark Kritzman, and David Turkington. "Facts About Factors." MIT Sloan School Working Paper 5128-15 (2015).

Dempster, A. P. "Logicist Statistics I. Models and Modeling." Statistical Science 13, no. 3 (1998): 248-276.

Doeswijk, Ronald, Trevin Lam, and Laurens Swinkels. "The Global Multi-Asset Market Portfolio, 1959-2012." Financial Analysts Journal 70, no. 2 (2014): 26-41.

Elton, Edwin J, Martin J Gruber, and Christopher R Blake. "Fundamental Economic Variables, Expected Returns, and Bond Fund Performance." Journal of Finance 50, no. 4 (1995): 12291256.

Ennis, Richard M, and Michael D Sebastian. "A Critical Look at the Case for Hedge Funds." Journal of Portfolio Management 29, no. 4 (2003): 103-112.

Eun, Cheol S, and Bruce G Resnick. "Exchange Rate Uncertainty, Forward Contracts, and International Portfolio Selection." Journal of Finance 43, no. 1 (1988): 197-215.

Fama, Eugene F., and Kenneth R. French. "The cross-section of expected stock returns." the Journal of Finance 47, no. 2 (1992): 427-465.

Fama, Eugene F., and Kenneth R. French. "Common risk factors in the returns on stocks and bonds." Journal of Financial Economics 33, no. 1 (1993): 3-56. 
Fama, Eugene F., and G. William Schwert. "Asset returns and inflation." Journal of Financial Economics 5, no. 2 (1977): 115-146.

Ferson, Wayne E, and Campbell R Harvey. "The Risk and Predictability of International Equity Returns." Review of Financial Studies 6, no. 3 (1993): 527-566.

Fung, William, and David A Hsieh. "Risk in Fixed-Income Hedge Fund Styles." Journal of Fixed Income 12, no. 2 (2002): 6-27.

Goetzmann, William, Jonathan Ingersoll, Matthew Spiegel, and Ivo Welch. "Sharpening Sharpe Ratios." NBER Working Paper No. 9116 (2002).

Goldberger, Arthur Stanley. A Course in Econometrics. Harvard University Press, 1991.

Hasanhodzic, Jasmina, and Andrew W Lo. "Can Hedge-Fund Returns Be Replicated?: The Linear Case." Journal of Investment Management 5, no. 2 (2007): 5-45.

Hayes, Mark. James A. Primbs, and Ben Chiquoine. "A Penalty Cost Approach to Strategic Asset Allocation with Illiquid Asset Classes." Journal of Portfolio Management 41, no. 2 (2015): 33-41.

He, Ling T, James R Webb, and F.C. Neil Myer. "Interest Rate Sensitivities of REIT Returns." International Real Estate Review 6, no. 1 (2003): 1-21.

Hoevenaars, Roy PMM, Roderick DJ Molenaar, Peter C. Schotman, and Tom BM Steenkamp. "Strategic asset allocation with liabilities: Beyond stocks and bonds." Journal of Economic Dynamics and Control 32, no. 9 (2008): 2939-2970. 
Ilmanen, Antti. Expected Returns: An Investor's Guide to Harvesting Market Returns. Wiley, 2011.

Idzorek, Thomas M., and Maciej Kowara. "Factor-Based Asset Allocation vs. Asset-Class-Based Asset Allocation." Financial Analysts Journal 69, no. 3 (2013): 19-29.

Jaeger, Lars, and Christian Wagner. "Factor Modeling and Benchmarking of Hedge Funds: Can Passive Investments in Hedge Fund Strategies Deliver?" Journal of Alternative Investments 8, no. 3 (2005): 9-36.

Jaffe, Jeffrey F, and Gershon Mandelker. "The "Fisher Effect" for Risky Assets: An Empirical Investigation." Journal of Finance 31, no. 2 (1976): 447-458.

Jorion, Philippe. "Bayes-Stein estimation for portfolio analysis." Journal of Financial and Quantitative Analysis 21, no. 03 (1986): 279-292.

Jurek, Jakub W, and Erik Stafford. "The Cost of Capital for Alternative Investments." Journal of Finance, forthcoming.

Kritzman, Mark. "The Optimal Currency Hedging Policy with Biased Forward Rates." Journal of Portfolio Management 19, no. 4 (1993): 94-100.

Leibowitz, Martin L, and Roy D Henriksson. "Portfolio Optimization within a Surplus Framework." Financial Analysts Journal 44, no. 2 (1988): 43-51.

Lo, Andrew W. "Risk Management for Hedge Funds: Introduction and Overview." Financial Analysts Journal 57, no. 6 (2001): 16-33. 
Ludvigson, Sydney C, and Serena Ng. "Macro Factors in Bond Risk Premia." Review of Financial Studies 22, no. 12 (2009): 5027-5067.

Markowitz, Harry. "Portfolio Selection." Journal of Finance 7, no. 1 (1952): 77-91.

Markowitz, Harry. "Utility of Wealth." Journal of Political Economy 60, no. 2 (1952): 151-158.

Merton, Robert C. "Lifetime Portfolio Selection Under Uncertainty: The Continuous-Time

Case." The Review of Economics and Statistics 51, no. 3 (1969): 247-257.

Merton, Robert C. "Optimum Consumption and Portfolio Rules in a Continuous-Time Model." Journal of Economic Theory 3 (1971): 373-413.

Merton, Robert C. "An Intertemporal Capital Asset Pricing Model." Econometrica 41, no. 5 (1973): 867-887.

Michaud, Richard O. "The Markowitz Optimization Enigma: Is 'Optimized' Optimal." Financial Analysts Journal 45, no. 1 (1989): 31-42.

Nelson, Charles R. "Inflation and Rates of Return on Common Stocks." Journal of Finance 31, no. 2 (1976): 471-483.

Perold, Andre F, and Evan C Schulman. "The Free Lunch in Currency Hedging: Implications for Investment Policy and Performance Standards." Financial Analysts Journal 44, no. 3 (1988): 4550.

Plerou, Vasiliki, Parameswaran Gopikrishnan, Bernd Rosenow, Luis A. Nunes Amaral, Thomas Guhr, and H. Eugene Stanley. "Random matrix approach to cross correlations in financial data." Physical Review E 65, no. 6 (2002): 066126. 
Qian, Edward. "Risk Parity Portfolios." PanAgora Asset Management Research Paper (2005).

Qian, Edward. "Risk Parity and Diversification." Journal of Investing 20, no. 1 (2011): 119-127.

Quaranta, Anna Grazia and Alberto Zaffaroni. "Robust Optimization of Conditional Value at Risk and Portfolio Selection." Journal of Banking and Finance 32 (2008): 2046-2056.

Rockafellar, R. Tyrrell and Stanislav Uryasev. "Optimization of Conditional Value-at-Risk." Journal or Risk 2 (2000): 21-42.

Roncalli, Thierry, and Guillaume Weisang. "Risk parity portfolios with risk factors." Available at SSRN 2155159 (2012).

Rosenberg, Barr, and Vinay Marathe. Common factors in security returns: Microeconomic determinants and macroeconomic correlates. No. 44. University of California at Berkeley, 1976.

Ross, Stephen A. "The arbitrage theory of capital asset pricing." Journal of economic theory 13, no. 3 (1976): 341-360.

Samuelson, Paul A. "Lifetime Portfolio Selection by Dynamic Stochastic Programming." The Review of Economics and Statistics 51, no. 3 (1969): 239-246.

Sanders, Anthony B. "A Note on the Relationship Between Corporate Bonds and Equity REITs." Real Estate Finance 1, no. 13 (1996): 61-63.

Sharifi, S., M. Crane, A. Shamaie, and H. Ruskin. "Random Matrix Theory for Portfolio Optimization: A Stability Approach." Physica A 335 (2004): 629-643.

Sharpe, William F. "Capital asset prices: A theory of market equilibrium under conditions of risk." Journal of Finance 19, no. 3 (1964): 425-442. 
Siegmann, Aren, and Andre Lucas. "Explaining Hedge Fund Investment Styles by Loss Aversion." Working Paper (2002).

Tibshirani, Robert. "Regression shrinkage and selection via the lasso." Journal of the Royal Statistical Society. Series B (Methodological) (1996): 267-288.

Treynor, Jack L. and Fischer Black. "How to Use Security Analysis to Improve Portfolio Selection.” The Journal of Business 46, no. 1 (1973): 66-86.

Van den Goorbergh, Rob, Roderick Molenaar, Onno W. Steenbeek, and Peter Vlaar. "Risk models with jumps and time-varying second moments." Working Paper (2011).

Xiong, James X. and Thomas M. Idzorek. "The Impact of Skewness and Fat Tails on the Asset Allocation Decision.” Financial Analysts Journal 67, no. 2 (2011): 23-35. 